\title{
Effect of Suryanamaskar on Occupational Stress among it Professionals
}

\section{Varsha SV}

Assistant Professor, Department of Physiology, Sri Siddartha Institute of Medical Science and Research Centre, Karnataka, India

Keywords: Occupational stress, Suryanamaskar, Software employees, Yoga

\section{Corresponding author}

Varsha SV

Assistant Professor, Department of Physiology, Sri Siddartha Institute of Medical Science and Research Centre, Karnataka, India

E-mail: drvarshasv@gmail.com

\begin{abstract}
$\mathrm{W}$ ith high number of young people taking up IT jobs and facing stressful life affecting their quality of life; there is a high degree of necessity to find the tools which can reduce stress levels among them. Yoga may be regarded as one such tool. Suryanamaskar a form of yogic exercise is well-known, but there are very few evidence-based studies in the past on the effects of suryanamaskar on stress. Hence present study was undertaken to assess the effects of suryanamaskar on professional stress by measuring it using Professional Life Stress Scale (PLSS) before and after the intervention of 30 days of suryanamaskar. It was noticed that, the stress score was reduced significantly from problematic to moderate level after the intervention. Suryanamaskar may be a useful tool, to be practiced on a daily basis, especially in the IT industry, which can help to alleviate stress, raise the quality of life of employees and thus productivity. However, detailed studies employing larger sample size and advanced methods are recommended to understand the scope of suryanamaskar further.
\end{abstract}

In recent decades, IT has become the career option of choice for many young educated Indians, for whom it offers relatively higher salaries, as well as an opportunity to live and work outside of India. But on the other hand, the nature of job has a negative impact on the employee's physical and mental health. IT work tends to be highly stressful with tyranny of deadlines and project timelines, and software engineers are always struggling to meet unrealistic deadlines and firefighting last-minute crisis (Ranjit and Mahespriya, (2012).

Stress is a necessity for maintaining homeostasis, but turns out to be harmful when it becomes overwhelming and interrupts homeostasis. Stress stimulates the nervous system, overburdens the adrenal glands and lowers immunity. Stress causes an imbalance of the parasympathetic and sympathetic nervous system which lead to disturbances of homeostasis in the body and thus quality of life (Gawali and Dhule, 2013).
With higher number of young people taking up IT jobs and facing stressful life affecting their quality of life; there is a high degree of necessity to find the tools which can reduce stress levels among them. Yoga may be regarded as one such tool. Yoga helps you to access an inner strength that allows you to face overwhelming fears, frustrations, and challenges of everyday life. Surya Namaskar (SN), or Sun Salutation, is a yoga warmup routine based on a sequence of gracefully linked asanas (Jane MacMullen, 1988; Carol Mitchell 2003).

Suryanamaskar is the package of twelve asanas which involves the breathing awareness and physicalpostures. It includes various asanas such as -Pranamasana, Hastthothanasana, Pada hasthasana, Aswasanchalasana, Dandasana, Astanga namaskar, Bhujangasana, Tadasana (Saraswati, 1983; Datye, 1990). Suryanamaskar as a form of yogic exercise is wellknown, but there are very few evidence-based studies in the past on the effects of suryanamaskar on physiological 
changes especially on stress (Sinha et al., 2002; Bhavanani et al. 2011). Hence, the present study uses this as an opportunity to explore the effect of Suryanamaskar on professional stress among software employees.

\section{MATERIALS AND METHODS}

\section{Participants}

48 group A software employees from one of the IT company in Bangalore volunteered for the study. Subjects who regularly practice yoga or other physical activity/sports were not included. Subjects with history suggestive of neurological abnormalities, endocrinal disorders, those on drugs acting on Central Nervous System like antipsychotics, antidepressants, sedative-hypnotics were excluded from the study. Smokers and Chronic alcoholics too were excluded from the study. Final sample size after applying exclusion criteria was 32 . Subjects acted as self-controls.

\section{Design of the study}

Standard instructions were given to the respondents and were also informed about the confidentiality and anonymity of their responses. They were told to respond honestly. Participants were assessed for their professional stress on day 1 (pre-SN), and day 30 (post-SN) of the intervention using Professional Life Stress Scale (PLSS).

Subjects were asked to relax for $30 \mathrm{~min}$ on day1 and day 30 then given a participant information sheet and a consent form. After reading the participant information sheet, subjects were instructed to sign the consent form and complete the Professional Life Stress Scale (PLSS). The entire test administration was done in English.

\section{Professional Life Stress Scale}

PLSS was developed by David Fontana in 1989. It contains 22 questions which measures level of professional stress by assessing various domains of profession like work load, work environment, rewards etc. The scoring range is between 0 and 60 (Fontana, 1989). The scoring scale is represented in table 1.

Table 1: Scoring scale and severity of stress in PLSS

\begin{tabular}{ccc}
\hline Score & \multicolumn{2}{c}{ Severity of professional stress } \\
\hline $0-15$ & \multicolumn{2}{c}{ No stress } \\
\hline $16-30$ & & Moderate \\
$31-45$ & Stress & Problematic \\
$46-60$ & & Major problem \\
\hline
\end{tabular}

\section{Intervention: Suryanamaskar}

The suryanamaskar sessions were conducted in a yoga centre nearby workplace. The subjects were guided by a team of experts. Suryanamaskar trainers were experienced in teaching suryanamaskar for five years or more and were qualified for suryanamaskar training. The subjects were observed for medical conditions and contraindications. The attendance record for all the participants was maintained.

The suryanamaskar training session was done for first 2 days. Next 30 days the subjects were asked to perform suryanamaskar on their own and was monitored by expert instructors on a daily basis. Everyday suryanamaskar session included warm up, 15 rounds of suryanamaskar with mantras and breathing and cooling down (sitting position) which took approximately $25-30 \mathrm{~min}$. As there were many ways of performing suryanamaskar, a standard method (10 counts) of performing and a standard set of instructions was established and followed throughout the sessions. Participants were encouraged to maintain incidental recordings in a diary kept at the yoga centre where suryanamaskar sessions were conducted. It was made sure through the data sheet that they did not engage themselves in any other relaxation activity.

\section{Data Analysis}

The Descriptive statistics were used, i.e., mean and standard deviation (SD) for describing the parameters. The data was analysed using SPSS 20.0. Paired 't' test was used to check the difference between professional stress before and after suryanamaskar intervention.

\section{RESULTS AND DISCUSSION}

All the subjects were in the age group 30-50 years with mean age $38.34 \pm 7.62$ years had BMI $22.06 \pm 2.14 \mathrm{~kg} / \mathrm{m}^{2}$. Subjects slept for $7.6 \pm 1.3$ hours per day during the study.

Table 2: Comparison of professional stress before and after Suryanamaskar intervention

\begin{tabular}{|c|c|c|c|}
\hline Parameter & $\begin{array}{c}\text { Pre-SN } \\
\text { intervention }\end{array}$ & $\begin{array}{c}\text { Post- SN } \\
\text { intervention }\end{array}$ & $P$ value \\
\hline & Mean \pm SD & Mean士SD & \\
\hline PLSS score & $\begin{array}{c}32.4 \pm 8.57 \\
\text { (Problematic) }\end{array}$ & $\begin{array}{l}21.1 \pm 6.28 \\
\text { (Moderate) }\end{array}$ & $0.0449 *$ \\
\hline
\end{tabular}

PLSS - Professional Life Stress Scale; In brackets - Classification of stress score of PLSS (Fontana, 1989); $* \mathrm{P}<0.05$ significant, $* * * \mathrm{P}<0.005$ highly significant difference. 
Table 2 shows comparison of professional stress before and after the intervention. Our study clearly showed significant difference ( $p$ value 0.0449 ) in professional stress before Starting practice of $\mathrm{SN}(32.4 \pm 8.57)$ and after 30 days of regular SN (21.1 \pm 6.28$)$. Even though there was moderate stress (PLSS score 16-30) after the intervention, the score was significantly reduced compared to pre-SN, which had stress score in the range of problematic stress (PLSS score 31-45). The downward trend in the change of stress score is presented in Fig. 1.

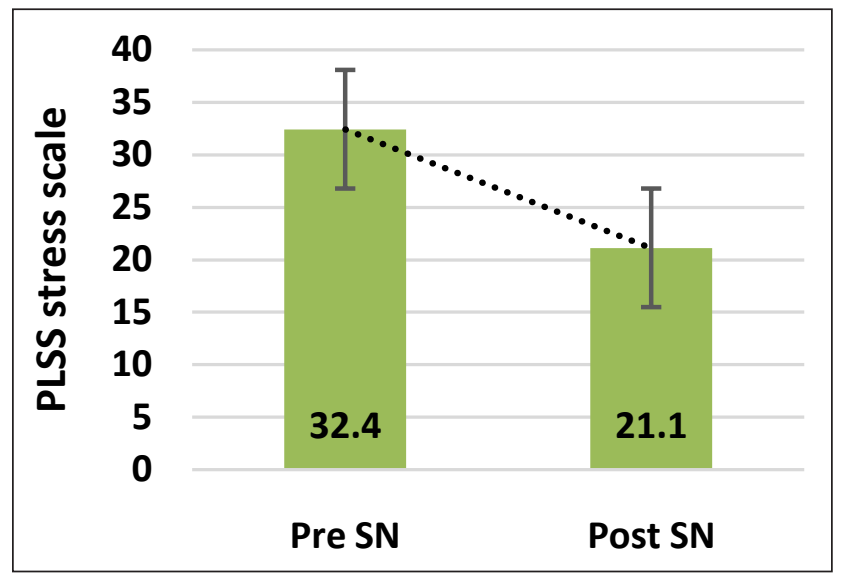

Fig. 1: Comparison of professional stress and its trend before and after Suryanamaskar intervention

Aim of the present study was to examine the effect of Suryanamaskar on professional stress among IT employees. It was evidenced that, the professional stress experienced by the employees was reduced after the $\mathrm{SN}$ intervention compared to pre intervention levels. The practice of yoga is a tremendous gift from our Indian Culture. Only recently we have begun to understand the vast potential and health benefits of yoga.

There are few Similar researches conducted to assess the effects of SN on stress levels. A study on college students by Manoj Sharma et al., found that suryanamaskar effectively improves the stress levels (Sharma, 2014). A study by Sang dol Kim et al., indicate that yogic exercises would reduce life stress and even lower postprandial blood glucose levels in nursing students (Sang Dol Kim, 2014). In a study by N. Hartfiel et al., it was found that 8 week program of 'workplace yoga' resulted in significant reductions in perceived stress and improved psychological well-being (Hartfiel et al., 2012). Another study by Hartfiel et al., reported that there was significant increase in resilience to stress, and substantial improvements in composure, clear-mindedness, energy and confidence after a 6-week yoga program in a British university (Hartfiel et al. 2011).

The present research is a step towards adding to the data of previous studies on suryanamaskar and its physiological benefits as evidenced by other studies showing improvement of pulmonary function, respiratory pressures, hand grip strength and endurance, and resting cardiovascular parameters (Bhavanani et al., 2011).

Even though the study was based on limited sample size, SN may be a useful tool, to be practiced for psychological health on a daily basis, especially in the IT industry, which can help to alleviate stress, raise the quality of life of employees and thus productivity. We recommend further detailed studies in this area by employing different age groups, other grades of professionals and assessment methods to check other physiological changes and understand molecular mechanisms involved.

As per the classification given by David Fontana for stress scores, moderate stress (score 16-30) needs to be reasonably reduced. Problematic Stress (score 31-45) is considered a real problem, and points to the need for remedial action. The longer the person works under problematic stress, the harder it gets to prevent the adverse effects of it. Hence professional stress needs careful evaluation and early mitigation (Fontana, 1989). This study will have implications in terms of use of suryanamaskar as a relaxation strategy for high stress professions and to reduce stress at a dispositional level.

\section{ACKNOWLEDGEMENTS}

We would like to thank the yoga experts who helped train and monitor the $\mathrm{SN}$ sessions and the subjects for volunteering enthusiastically in spite of their busy schedules.

\section{CONCLUSION}

It was evidenced that regular practice of Suryanamaskar had positive effect on professional stress alleviation. After further studies to explore its effect at molecular level, Suryanamaskar can be recommended in future stress management strategies to reap its beneficial effects.

\section{REFERENCES}

Bhavanani, A.B., Udupa, K. and Madanmohan, M. 2011. A comparative study of slow and fast suryanamaskar on physiological function. International Journal of Yoga, 4: 71. 
Carol Mitchell. 2003. Yoga on the ball. Inner traditions, pp. 48.

Datye, H.V. 1990. Suryanamaskar: Upasana aani Vyayam. Pune: Bharatiya Vichar Sadhana.

Fontana, D. 1989. Professional life stress scale adapted from Managing stress. The British Psychological Society and Routledge Ltd.

Gawali, S. and Dhule, S. 2013. Effect of yoga on anxiety levels in working women. International Journal of Science and Research, 2(12): 143-5.

Hartfiel, N., Burton, C., Rycroft-Malone, J., Clarke, G., Havenhand, J., Khalsa, S.B. and Edwards, R.T. 2012. Yoga for reducing perceived stress and back pain at work. Occupational Medicine, 62: 606-612.

Hartfiel, N., Havenhand, J., Khalsa, S.B., Clarke, G. and Krayer, A. 2011. The effectiveness of yoga for the improvement of well-being and resilience to stress in the workplace. Scand J. Work Environ Health, 37: 70-76.
Jane MacMullen. 1988. Ashtanga yoga. Yoga journal, pp. 68-70.

Ranjit, L. and Mahespriya, L. 2012. Study on job stress and quality of life of women software employees. International Journal of Research in Social Sciences, 2(2): 276-291.

Sang Dol Kim, 2014. Effects of Yogic Exercises on Life Stress and Blood Glucose Levels in Nursing Students J. Phys. Ther. Sci., 26.

Saraswati, S.S. 1983. Suryanamaskar - A technique of solar vitalization. Munger: Yoga Publications Trust.

Sharma, M.K. 2014. Effect of Suryanamaskar on stress level: International Journal of Creative Research Thoughts, 2(1).

Sinha, B., Ray, U.S., Pathak, A. and Selvamurthy, W. 2002. Energy cost and cardio respiratory changes during the practice of Surya Namasakr. Indian J. Physiol. Pharmacol., 48: 184-190. 